\title{
O Canada-Keep our specialty glorious and free
}

\author{
Brendon M. Stiles, MD
}

\footnotetext{
From the Division of Thoracic Surgery, Department of Cardiothoracic Surgery, New York-Presbyterian Hospital, Weill Cornell Medical College, New York, NY.

Disclosures: Author has nothing to disclose with regard to commercial support.

Received for publication Sept 29, 2016; accepted for publication Sept 29, 2016.

Address for reprints: Brendon M. Stiles, MD, Division of Thoracic Surgery, Department of Cardiothoracic

Surgery, Weill Medical College of Cornell University, New York-Presbyterian Hospital, Suite M404, 525

East 68th St, New York, NY 10021 (E-mail: brs9035@med.cornell.edu).

J Thorac Cardiovasc Surg 2017;153:498-9

$0022-5223 / \$ 36.00$

Copyright (c) 2016 Published by Elsevier Inc. on behalf of The American Association for Thoracic Surgery

http://dx.doi.org/10.1016/j.jtcvs.2016.09.064
}

I read with interest the review of thoracic surgery education in Canada by Grondin and Schieman. ${ }^{1}$ The article highlights several points worth considering. In Canada, the number of accredited programs is tightly regulated. Whether this is good or bad for the specialty as a whole and for health care in general could be debated at length. However, what is clear is that in such a system, accurately forecasting future workforce needs is critical. The shift to a competency-based evaluation system also is notable and similar to evaluation programs adopted by US residencies. Such a longitudinal system is likely more meaningful than pooled evaluations from individual rotations. However, along with this change has come a mind-numbing jumble of acronyms (RCPSC, CanMEDS, CATS, ITERS, ABSITE, FITER, and CBME) involved in the policy of training residents and assessing outcomes. Although the input from these groups and data from these examinations are important, I wonder if we have moved away from the central question that has long defined surgeons: "Can he or she operate?"

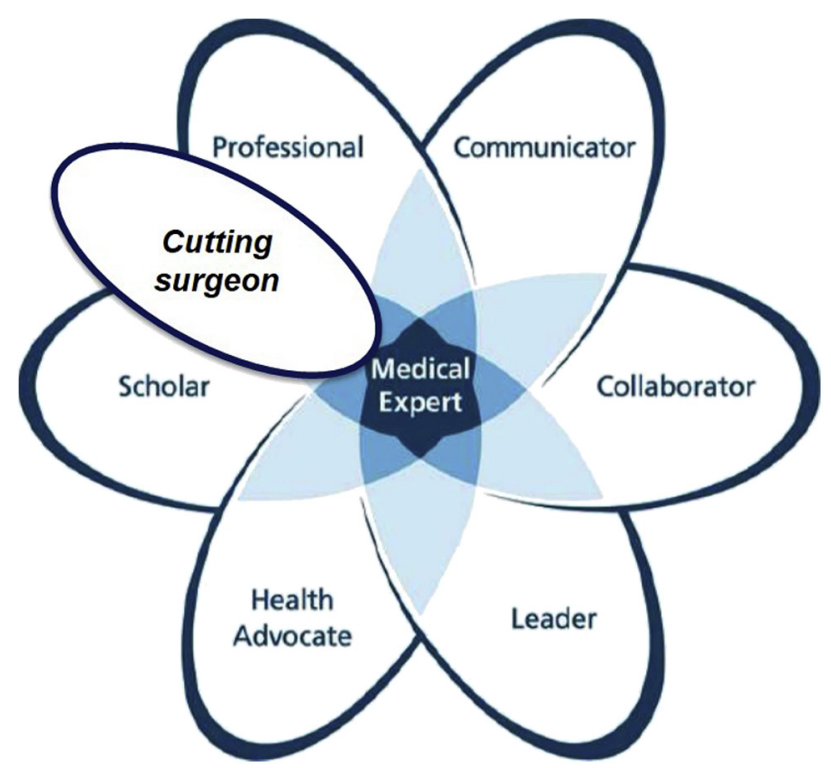

FIGURE 1. Where does technical excellence fit in competency requirements?

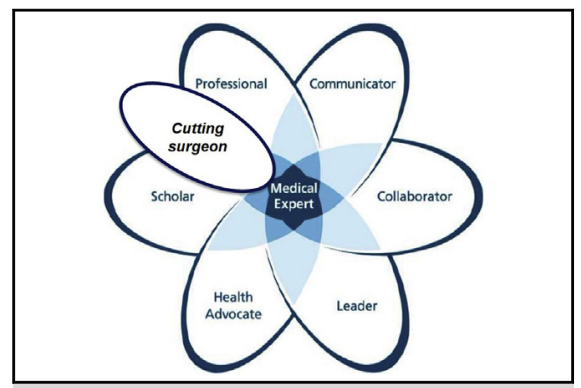

Where does technical excellence fit in competency requirements?

Central Message

Cardiothoracic residency training programs need to address the growing concern that today's graduating surgeons, although "competent," are not adequately prepared for independent surgical practice.

See Editorial page 493.

This quandary is highlighted by the authors' finding that thoracic residents are uncomfortable performing many core thoracic surgery procedures. ${ }^{2}$ More worrisome, junior attending thoracic surgeons reported that they could only confidently perform 7 of 18 procedures independently. This shortcoming is not unique to Canada. Work hour restrictions, a shift-work mentality, and excessive administrative responsibilities have taken valuable time from practical training everywhere. The public reporting and rigorous tracking of surgical outcome data also may contribute to a reluctance to "give up" cardiothoracic cases to residents. A survey of graduating US cardiothoracic residents revealed that they were routinely the operating surgeon in only 2 of 13 cardiac procedures. ${ }^{3}$ When even The New York Times is asking “Are Today's New Surgeons Unprepared?" it is clear that we have a problem.

Thus, it would seem that a crisis of surgical quality may be on the horizon. How do we best train cardiothoracic surgeons in this environment? We certainly have to make training more efficient. Early entry, integrated programs, and subspecialty specific tracks are the correct path to follow. We also need to take a clear-eyed, data-based approach to determine the technical quality of graduating residents and to direct future training efforts. In this regard, I commend Drs Grondin and Schieman ${ }^{1}$ for their long track record of investigation in education and work force needs. No one knows how to train and evaluate cardiothoracic surgeons better than cardiothoracic surgeons. Yes, it is critical that we ensure that our graduates 
are professionals, communicators, collaborators, leaders, health advocates, and scholars. But wouldn't it be nice to also see "cutting surgeon" or "technical expert" in one of those fancy, acronym-derived Venn diagrams? A renewed focus on technical excellence can be achieved only through increased operative experience, surgical mentorship, and practical, honest evaluation on the local level and through leadership in establishing standards for surgical technical competency requirements on the national level (Figure 1). We must continue to be a glorious and free specialty; surgical excellence matters.

\section{References}

1. Grondin SC, Schieman C. Thoracic surgery education in Canada. J Thorac Cardiovasc Surg. 2017:153:493-7.

2. Edwards J, Kelly E, Schieman C, Gelfand G, Grondin SC. Do new thoracic surgeons feel ready to operate? Self-reported comfort level of thoracic surgery trainees and junior thoracic surgeons with core thoracic surgery procedures. $J$ Surg Educ. 2011;68:270-81.

3. Shah AA, Aftab M, Tchantchaleishvili V, LaPar DJ, Stephens EH, Walters DM, et al. Characterizing the operative experience of cardiac surgical trainees: what are residents really doing in the operating room? Ann Thorac Surg. 2016;101: 2341-9.

4. Chen PW. Are today's new surgeons unprepared? The New York Times. December 12, 2013. Available at: http://well.blogs.nytimes.com/2013/12/12/are-todaysnew-surgeons-unprepared/. Accessed September 28, 2016. 